\title{
APLIKASI PERSAMAAN DEFERENSIAL BIASA MODEL EKSPONENSIAL DAN LOGISTIK PADA PERTUMBUHAN PENDUDUK KOTA SURABAYA
}

\author{
Arief Kurniawan $^{1}$, Iis Holisin², Febriana Kristanti ${ }^{3}$ \\ Program Studi Pendidikan Matematika, FKIP UMSurabaya \\ Ariefkurniawan0705@gmail.com
}

\begin{abstract}
ABSTRAK
Penelititan ini bertujuan untuk mendeskripsikan aplikasi persamaan diferensial pada model pertumbuhan penduduk Kota Surabaya yaitu model eksponensial dan model logistik dan menentukan model yang terbaik antara model eksponensial dan logistik untuk pendugaan jumlah penduduk Kota Suabaya. Metode yang digunakan dalam penelitian ini adalah penelitian deskriptif dengan pendekatan kualitatif yang dilakukan dengan cara melakukan observasi dan menganalisa subjek . Subjek penelitian adalah data jumlah penduduk Kota Surabaya tahun 2011 hingga 2015. Sedangkan untuk mengetahui keakuratan dan keabsahan data penelitian menggunakan triangulasi sumber. Untuk Triangulasi data yang digunakan berasal dari Dinas Kependudukan dan Catatan Sipil (Dispendukcapil) dan Badan Pusat Statistik (BPS) Kota Surabaya. Dari hasil penelitian diperoleh model eksponensial IV dengan bentuk persamaan $P(t)=3.024 .321 e(-0,00676) t$. Sedangkan untuk model pertumbuhan penduduk yang kedua yaitu model logistik dari hasil analisis diperoleh persamaan $P=3.388 .807(0,12051) e(0,05682) t+1$. Hasil penelitian juga menunjukkan dari kedua model pertumbuhan penduduk yang diperoleh bahwa model yang lebih akurat untuk pendugaan jumlah penduduk Kota Surabaya adalah model logistik.
\end{abstract}

Kata Kunci: model logistik, model eksponensial, persamaan deferensial.

\begin{abstract}
This research was aimed to describe the differential equations application of population growth model of Surabaya City that is exponential model and logistic model and determine the best model between exponential and logistic models for estimating the number of population in Surabaya. The method used in this research is descriptive research with qualitative approach which is conducted by observations and analyzes of the subject. The subject of this research was the population data of Surabaya city in 2011 to 2015. To know the accuracy and validity of the research data the researcher used triangulation. The triangulation used Department of Population and Civil Registration (Dispendukcapil) data and Central Statistics Agency (BPS) in Surabaya. The results were obtained exponential model in an equation form $P(t)=3.024 .321 e^{(-0.0676) t}$. While for logistic models were obtained two equations $P=\frac{3.388 .807}{(0,1204)(0, .05682)^{t}+1}$. The results also showed that from two models of population growth obtained that a more accurate model for estimating the population of Surabaya city was the logistic model.
\end{abstract}

Keywords: Exponential Model, Logistics Model, The Differential Equation.

\section{PENDAHULUAN}

Pertumbuhan penduduk suatu daerah merupakan hal penting karena dapat mempengaruhi kemajuan dan kemakmuran daerah tersebut. Tingkat pertumbuhan penduduk yang terlalu tinggi akan sangat beresiko menimbulkan berbagai masalah 
pada daerah tersebut, seperti tingkat pengangguran yang tinggi, kemiskinan, dan kelaparan. Namun disisi lain, dampak-dampak negatif di atas dapat dikurangi jika kita mampu mempersiapkan sarana yang cukup untuk menganstisipasi hal tersebut.

Surabaya adalah kota metropolitan terbesar kedua dengan luas wilayah \pm 52.087 Ha. Luas wilayah dengan 33.048 Ha merupakan daratan dan selebihnya 19.039 Ha merupakan wilayah laut yang dikelola oleh Pemerintah Kota Surabaya. Dari hasil sensus penduduk (Dispendukcapil) Surabaya dalam kurun waktu 3 tahun mencapai angka lebih dari 3 juta. Dengan luas Surabaya yang hanya sebesar itu, maka tingkat kepadatan penduduk di Surabaya akan semakin meningkat sejalan dengan laju pertumbuhan penduduknya yang terus meningkat. Hasil sensus penduduk (Dispendukcapil) Surabaya tahun 2010 sampai 2013 jumlah penduduk Kota Surabaya mengalami peningkatan rata-rata sebesar 177.973 jiwa. Pada tahun 2014 Menurun sebesar 346.793 jiwa, namun di tahun 2015 mengalami peningkatan lagi jumlah penduduk rata-rata sebesar 89.867 jiwa.

Agar tidak terjadi ledakan populasi yang dapat menimbulkan bencana, maka diperlukan perencanaan untuk pengendalian jumlah populasi. Salah satunya bisa dimulai dengan memprediksi pertumbuhan populasi penduduk Surabaya. Dari fenomena yang ada dapat dianalisis dengan menggunakan berbagai macam sudut pandang, salah satunya peristiwa yang ada dapat dipandang dalam bentuk model matematika. Contoh aplikasi matematika yang dapat diterapkan dalam kehidupan nyata adalah pemodelan dengan persamaan diferensial khususnya model populasi kontinu. Terdapat beberapa macam model pertumbuhan populasi diantarnya model populasi eksponensial dan model populasi logistik. Kontinu dalam hal ini berarti populasi bergantung waktu tanpa putus. Dari waktu ke waktu bentuk tiap model dimodifikasi sehingga dapat menggambarkan dengan lebih teliti keadaan sebenarnya.

Dari rumusan masalah di atas, peneliti mempunyai tujuan sebagai berikut.

1. Mendiskripsikan dan menemukan model eksponensial pertumbuhan penduduk Kota Surabaya.

2. Mendiskripsikan dan menemukan model Logistik pertumbuhan penduduk Kota Surabaya. 
3. Mengetahui model yang terbaik untuk pendugaan jumlah penduduk Kota Surabaya yang akan datang.

\section{METODE PENELITIAN}

Metode merupakan sarana dalam pencapaian tujuan penelitian yang digunakan oleh peneliti, sehingga penggunaan metode ini disesuaikan dengan masalah dan tujuan penelitian tersebut dilaksanakan. Sedangkan definisi dari metode penelitian adalah cara ilmiah untuk memperoleh data dengan kegunaan dan tujuan tertentu. Maka berdasarkan dari tujuan yang ingin dicapai, penelitian ini menggunakan metode deskriptis dengan pendekatan kualitatif.

Pendekatan kualitatif ini diambil karena dalam penelitian ini sasaran atau objek penelitian dibatasi agar data-data yang diambil dapat digali sebanyak mungkin serta agar dalam penelitian ini tidak dimungkinkan adanya pelebaran objek penelitian.

Penelitian ini merupakan jenis penelitian deskriptis dengan pendekatan kualitatif yang dimaksudkan untuk mengaplikasikan persamaan diferensial model populasi pada pertumbuhan penduduk di Kota Surabaya khususnya model populasi eksponensial dan logistik.

\section{HASIL PENELITIAN DAN PEMBAHASAN}

1. Analisis Model Eksponensial Pertumbuhan Penduduk Kota Surabaya

Nugroho (2011:58-59) menjelaskan beberapa asumsi yang digunakan dalam pendugaan pertumbuhan penduduk secara eksponensial, yaitu:
a. Laju kelahiran dan kematian konstan
b. Tidak ada struktur genetik
c. Tidak ada struktur perbedaan umur dan ukuran
d. Tidak ada waktu tunda

Diandaikan $P(t)$ adalah banyaknya individu pada suatu populasi yang mempunyai laju kelahiran dan kematian konstan berturut-turut $\beta$ dan $\nsim$. Dinamika suatu populasi dapat digambarkan oleh persamaan diferensial.

$$
\frac{d P}{d t}=k P(t)
$$


dengan $k=\beta-\partial$

Dinamika suatu populasi model eksponensial dapat digambarkan oleh persamaan diferensial (2.13). Pada model persamaan diferensial (1.1) merupakan persamaan diferensial separabel, sehingga kita dapat mencari solusi umumnya sebagai berikut :

$$
\begin{aligned}
\int \frac{d P}{P} & =\int k \cdot d t \\
\ln P(t) & =k t+c \\
e^{\ln P(t)} & =e^{k t+c} \\
P(t) & =e^{k t+c}
\end{aligned}
$$

Jika diberikan kondisi awal $t=0$ dan $P(0)=P_{0}$ maka diperoleh nilai $c=\ln$ $P_{0}$ sehingga bila nilai $c$ disubstitusikan ke dalam (1.2) akan menghasilkan,

$$
\begin{aligned}
& P(t)=e^{k t+\ln P_{0}} \\
& P(t)=e^{k t} e^{\ln P_{0}} \\
& P(t)=P_{0} e^{k t}
\end{aligned}
$$

Persamaan (1.3) merupakan bentuk solusi khusus dari model pertumbuhan eksponensial. Dari persamaan tersebut dapat dilihat jika nilai $k$ positif maka populasi akan meningkat secara eksponensial, sebaliknya jika nilai $k$ negatif maka populasi akan semakin punah. Dari persamaan (1.3) dapat diperoleh persamaan laju intrinsik $(k)$

$$
k=\frac{\ln \frac{P_{t}}{P_{0}}}{t}
$$

Secara keseluruan terdapat lima model eksponensial dengan laju intrinsik yang berbeda-beda yang akan digunakan melakukan pendugaan jumlah penduduk Kota Surabaya pada tahun 2011 sampai tahun 2015. Berikut ini adalah hasil dari model eksponensial diantaranya :

a. Model eksponensial I, bentuk persamaannya $P(t)=3.024 .321 e^{(0,032931) t}$, dengan laju pertumbuhan relatifnya positif adalah 3,29\% per tahun.

b. Model eksponensial II, bentuk persamaannya $P(t)=3.024 .321 e^{(0,02830) t}$, dengan laju pertumbuhan relatifnya positif adalah $2,83 \%$ per tahun.

c. Model eksponensial III, bentuk persamaannya $P(t)=3.024 .321 e^{(-0,01936) t}$, dengan laju pertumbuhan relatifnya negatif adalah 1,93\% per tahun. 
d. Model eksponensial IV, bentuk persamaannya $P(t)=3.024 .321 e^{(-0,00676) t}$, dengan laju pertumbuhan relatifnya negatif adalah $0,67 \%$ per tahun.

e. Model eksponensial $\mathrm{V}$, bentuk persamaannya $P(t)=3.024 .321 e^{(0,00877) t}$, dengan laju pertumbuhan relatifnya positif adalah $0,87 \%$ per tahun.

Hasil yang diperoleh kemudian akan dibandingkan dengan data jumlah penduduk dari Dinas Kependudukan dan Catatan Sipil (Dispendukcapil) Kota Surabaya. Model terbaik adalah model yang menghasilkan data-data yang cukup mendekati (galat terkecil) dengan data sebenarnya, atau jika ditampilkan dalam bentuk grafik maka model terbaik adalah model grafik yang paling mendekati dengan grafik data sebenarnya. Hasil perhitungan jumlah penduduk di Kota Surabaya berdasarkan kelima model eksponensial dengan nilai laju pertumbuhan relatifnya yang berbeda-beda dapat dilhat pada Tabel 1.2

Tabel 1.2 Hasil Perhitungan Jumlah Penduduk Kota Surabaya Berdasarkan Model Eksponensial

\begin{tabular}{|l|c|c|c|c|c|c|}
\hline \multirow{2}{*}{ Tahun } & \multirow{2}{*}{ Dispendukcapil } & \multicolumn{5}{|c|}{ Model Ekponensial } \\
\cline { 3 - 7 } & & Model I & Model II & Model III & Model IV & Model V \\
\hline 2011 & 3.024 .321 & 3.024 .321 & 3.024 .321 & 3.024 .321 & 3.024 .321 & 3.024 .321 \\
\hline 2012 & 3.125 .576 & 3.125 .565 & 3.110 .185 & 2.965 .132 & 3.002 .548 & 3.050 .087 \\
\hline 2013 & 3.200 .454 & 3.232 .165 & 3.200 .453 & 2.908 .871 & 2.982 .747 & 3.077 .945 \\
\hline 2014 & 2.853 .661 & 3.342 .400 & 3.293 .303 & 2.853 .678 & 2.963 .076 & 3.106 .057 \\
\hline 2015 & 2.943 .528 & 3.456 .395 & 3.388 .866 & 2.799 .531 & 2.943 .536 & 3.134 .427 \\
\hline
\end{tabular}

Untuk dapat mengetahui hasil perhitungan model-model diatas yang benarbenar mendekati dengan data Dispendukcapil, maka akan ditampilkan dalam bentuk Gambar 1.2

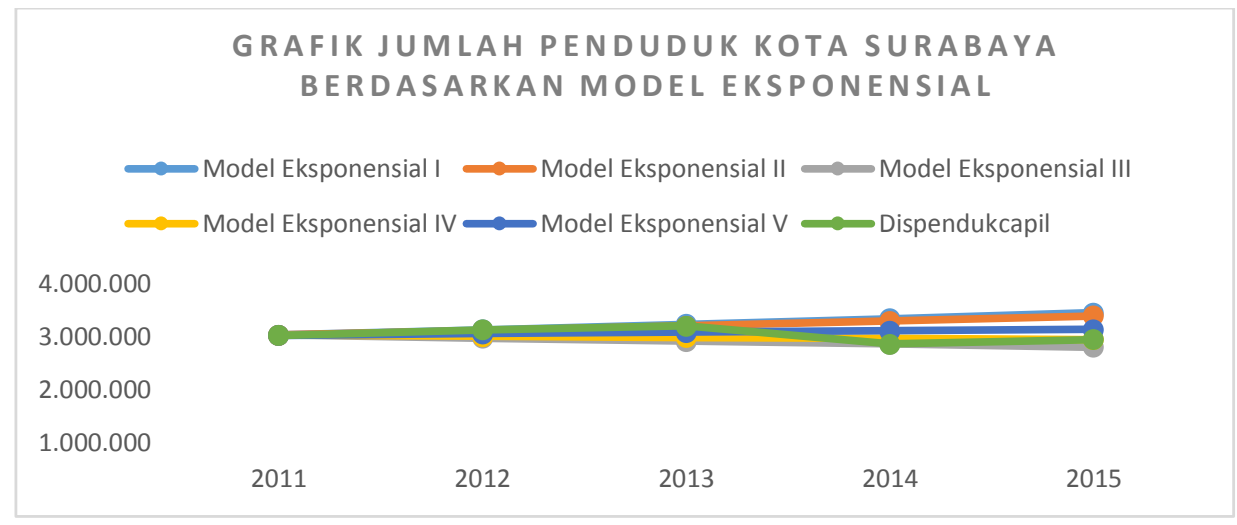

Gambar 1.2 Grafik jumlah penduduk Kota Surabaya berdasarkan data Dipendukcapil dan model eksponensial 
Pada Gambar 1.2 terlihat bahwa grafik yang paling mendekati dengan grafik jumlah penduduk Dispendukcapil Kota Surabaya adalah grafik model eksponensial IV. Jadi model eksponensial yang terbaik adalah model eksponensial IV dengan nilai laju intrinsik $k=-0,00676$, atau dapat pula ditulis

$$
P(t)=3.024 .321 e^{(-0,00676) t}
$$

\section{Analisis Model Logistik Pertumbuhan Penduduk Kota Surabaya}

Stewart (1999:38-39) Mengatakan persamaan diatas menyiratkan bahwa laju pertumbuhan pada awalnya hampir sebanding dengan besar populasi. Dalam pekataan lain, laju pertumbuhan relatif hampir konstan jika populasi kecil. Populasi maksimum yang dapat dipertahankan oleh lingkungan dalam jangka panjang. Bentuk yang paling sederhana untuk laju pertumbuhan relatif yang mengakomodasi asumsi ini adalah

$$
\frac{1}{P} \frac{d P}{d t}=k\left(1-\frac{P}{K}\right)
$$

Persamaan 2.1 kalikan dengan $\mathrm{P}$, kita peroleh model untuk pertumbuhan populasi yang dikenal sebagai persamaan diferensial logistik :

$$
\frac{d P}{d t}=k P\left(1-\frac{P}{K}\right)
$$

Berdasarkan persamaan logistik (2.2) merupakan persamaan diferensial terpisahkan sehingga dapat diselesaikan secara eksplisit dengan mencari solusi umum persamaan logistik dapat diperoleh melalui langkah-langkah berikut ini:

$$
\begin{aligned}
\frac{d P}{d t} & =k P\left(1-\frac{P}{K}\right) \\
\frac{d P}{P\left(1-\frac{P}{K}\right)} & =k d t \\
\int \frac{d P}{P\left(1-\frac{P}{K}\right)} & =\int k d t \\
\int \frac{d P}{P-\frac{P^{2}}{K}} & =\int k d t \\
\int \frac{K d P}{K P-P^{2}} & =\int k d t \\
\ln P-\ln (K-P) & =k t+c \\
\ln \left(\frac{P}{K-P}\right) & =k t+c
\end{aligned}
$$




$$
\begin{aligned}
\frac{P}{K-P} & =e^{k t+c} \\
P & =e^{k t+c}(K-P) \\
P & =K e^{k t+c}-P e^{k t+c} \\
P & +P e^{k t+c}=K e^{k t+c} \\
P\left(1+e^{k t+c}\right) & =K e^{k t+c} \\
P & =\frac{K e^{k t+c}}{1+e^{k t+c}}
\end{aligned}
$$

Dari persamaan (2.3) jika diberikan nilai awal $t=0$ dan $P(0)=P_{o}$ kemudian disubstitusikan ke dalam (2.3) maka akan diperoleh nilai $c=\ln \left(P_{0} / K-P_{0}\right)$ selanjutnya nilai $c$ tersebut disubstitusikan kembali ke dalam persamaan (2.3), sehingga diperoleh solusi khusus dari model logistik seperti berikut,

$$
\begin{aligned}
& P=\frac{K e^{k t+\ln \left(\frac{P_{0}}{K-P_{0}}\right)}}{1+e^{k t+\ln \left(\frac{P_{0}}{K-P_{0}}\right)}} \\
& P=\frac{K e^{k t}\left(\frac{P_{0}}{K-P_{0}}\right)}{1+e^{k t}\left(\frac{P_{0}}{K-P_{0}}\right)} \\
& P=\frac{\frac{K e^{k t} P_{0}}{K-P_{0}}}{\frac{K-P_{0}+e^{k t P_{0}}}{K-P_{0}}} \\
& P=\frac{K e^{k t} P_{0}}{K-P_{0}+e^{k t} P_{0}} \\
& P=\frac{K P_{0}}{\left(K-P_{0}+e^{k t} P_{0}\right) e^{-k t}} \\
& P=\frac{K P_{0}}{\left(K e^{-k t}-P_{0} e^{k t}+P_{0}\right)} \\
& P=\frac{K}{\left(\frac{K}{P_{0}} e^{-k t}-e^{-k t}+1\right)}
\end{aligned}
$$

Sehingga diperoleh persamaan solusi khusus dari model logistik :

$$
P=\frac{K}{e^{-k t}\left(\frac{K}{P_{0}}-1\right)+1}
$$

Jika persamaan 2.4 dilimitkan $t \rightarrow \infty$, didapatkan (untuk $k>0$ ) :

$$
N_{\text {max }}=\lim _{t \rightarrow \infty} N=K=\frac{a}{b}
$$

Berdasarkan penejelasan verhlust laju pertumbuhan dan daya tampung (carrying capacity) dapat diperkirakan dengan rentang waktu pengambilan data yang diinginkan. Dalam penelitian ini,dilakukan beberapa perkiraan laju 
pertumbuhan dan daya tampung (carrying capacity) berdasarkan interval waktu pengambilan sampel $\Delta t$ untuk kemudian dilakukan analisis terhadah model.

Model logistik pada penelitian ini menggunakan interval waktu yaitu yang pertama dengan menggunakan tiga tahun pertama. Jika $P_{0}$ adalah populasi pada saat $t=0, P_{1}$ pada saat waktu $t=1$ dan $P_{2}$ pada waktu $t=2$, maka dari persamaaan (2.4) dapat diperoleh :

untuk $t=1$,

$$
\begin{aligned}
P_{1} & =\frac{\frac{a}{b}}{e^{-k(1)}\left(\frac{a}{P_{0}}-1\right)+1} \\
& =\frac{a b P_{0}}{b\left(b P_{0}+a e^{-k}-b P_{0} e^{-k}\right)} \\
\frac{1}{P_{1}} & =\frac{b P_{0}+a e^{-k}-b P_{0} e^{-k}}{a P_{0}} \\
& =\frac{b}{a}+\frac{e^{-k}}{P_{0}}-\frac{b P_{0} e^{-k}}{a P_{0}} \\
& =\frac{b}{a}\left(1-e^{-k}\right)+\frac{e^{-k}}{P} \\
\frac{b}{a}\left(1-e^{-k}\right) & =\frac{1}{P_{1}}-\frac{e^{-k}}{P_{0}}
\end{aligned}
$$

Untuk $t=2$, dengan cara yang sama diperoleh :

$$
\frac{b}{a}\left(1-e^{-k}\right)=\frac{1}{P_{2}}-\frac{e^{-2 k}}{P_{0}}
$$

Untuk mengeliminasi $\frac{b}{a}$ pada persamaan (2.5) dan (2.6), perlu dilakukan pembagian maka diperoleh

$$
\begin{aligned}
& \frac{\frac{b}{a}\left(1-e^{-k}\right)=\frac{1}{P_{2}}-\frac{e^{-2 k}}{P_{0}}}{\frac{b}{a}\left(1-e^{-k}\right)=\frac{1}{P_{1}}-\frac{e^{-k}}{P_{0}}} \\
& 1+e^{-k}=\frac{\frac{1}{P_{2}}-\frac{e^{-2 k}}{P_{0}}}{\frac{1}{P_{1}}-\frac{e^{-k}}{P_{0}}} \\
& e^{-k}=\left(\frac{P_{0} P_{1}-P_{1} P_{2} e^{-2 k}}{P_{0} P_{2}-P_{1} P_{2} e^{-k}}\right)-\left(\frac{P_{0} P_{2}-P_{1} P_{2} e^{-k}}{P_{0} P_{2}-P_{1} P_{2} e^{-k}}\right) \\
& e^{-k}=\frac{P_{0}\left(P_{2}-P_{1}\right)}{P_{2}\left(P_{1}-P_{0}\right)}
\end{aligned}
$$


Substitusikan persamaan (2.7) ke (2.5), maka :

$$
\begin{aligned}
\frac{b}{a}\left(1-\frac{P_{0}\left(P_{2}-P_{1}\right)}{P_{2}\left(P_{1}-P_{0}\right)}\right) & =\frac{1}{P_{1}}-\frac{\frac{P_{0}\left(P_{2}-P_{1}\right)}{P_{2}\left(P_{1}-P_{0}\right)}}{P_{0}} \\
\frac{b}{a}\left(\frac{P_{0}\left(P_{2}-P_{1}\right)}{P_{2}\left(P_{1}-P_{0}\right)}-\frac{P_{0}\left(P_{2}-P_{1}\right)}{P_{2}\left(P_{1}-P_{0}\right)}\right) & =\frac{P_{2}\left(P_{1}-P_{0}\right)-\left(P_{2}-P_{1}\right)}{P_{1} P_{2}\left(P_{1}-P_{0}\right)} \\
\frac{b}{a}=\frac{\frac{P_{2}\left(P_{1}-P_{0}\right)-\left(P_{2}-P_{1}\right)}{P_{1} P_{2}\left(P_{1}-P_{0}\right)}}{\frac{P_{2}\left(P_{1}-P_{0}\right)-P_{0}\left(P_{2}-P_{1}\right)}{P_{2}\left(P_{1}-P_{0}\right)}} & =\frac{P_{1}^{2}-P_{0} P_{2}}{P_{1}\left(P_{1} P_{0}-2 P_{0} P_{2}+P_{1} P_{2}\right)} \\
\frac{a}{b} & =\frac{P_{1}\left(P_{1} P_{0}-2 P_{0} P_{2}+P_{1} P_{2}\right)}{P_{1}{ }^{2}-P_{0} P_{2}}
\end{aligned}
$$

Sehingga persamaan daya tampung (carriying capacity) dapat dituliskan menjadi :

$$
K=\frac{P_{1}\left(P_{1} P_{0}-2 P_{0} P_{2}+P_{1} P_{2}\right)}{P_{1}{ }^{2}-P_{0} P_{2}}
$$

Secara keseluruan terdapat lima model logistik dengan laju intrinsik yang berbeda-beda yang akan digunakan melakukan pendugaan jumlah penduduk Kota Surabaya pada tahun 2011 sampai tahun 2015. Berikut ini adalah hasil dari model logistik diantaranya:

a. Model logistik I, bentuk persamaannya $=\frac{3.388 .807}{(0,12051) e^{(-0,35838) t}+1}$, dengan laju pertumbuhan relatifnya negatif adalah $35,8 \%$ per tahun.

b. Model logistik II, bentuk persamaannya $=\frac{3.388 .807}{(0,12051) e^{(-0,35839) t}+1}$, dengan laju pertumbuhan relatifnya negatif adalah $35,8 \%$ per tahun.

c. Model logistik III, bentuk persamaannya $=\frac{3.388 .807}{(0,12051) e^{(0,14737) t}+1}$, dengan laju pertumbuhan relatifnya positif adalah $14,7 \%$ per tahun.

d. Model logistik IV, bentuk persamaannya $=\frac{3.388 .807}{(0,12051) e^{(0,05682) t}+1}$, dengan laju pertumbuhan relatifnya positif adalah $5,6 \%$ per tahun.

e. Model logistik V, bentuk persamaannya $=\frac{3.388 .807}{(0,12051) e^{(-0.12814) t}+1}$, dengan laju pertumbuhan relatifnya negatif adalah $12,8 \%$ per tahun.

Hasil yang diperoleh kemudian akan dibandingkan dengan data jumlah penduduk dari Dispendukcapil Kota Surabaya. Model terbaik adalah model yang menghasilkan data-data yang cukup dekat (galat terkecil) dengan data sebenarnya atau jika ditampilkan dalam bentuk grafik maka model terbaik adalah model grafik yang paling mendekati dengan grafik yang dihasilkan dari data seebenarnya. Hasil 
perhitungan jumlah penduduk di Kota Surabaya berdasarkan kelima model logistik dengan nilai laju intrisik yang berbeda-beda dapat dilhat Tabel 4.7

Tabel 4.7 Hasil Perhitungan Jumlah Penduduk Kota Surabaya Berdasarkan Model Eksponensial

\begin{tabular}{|c|c|c|c|c|c|c|}
\hline \multirow{2}{*}{ Tahun } & \multirow{2}{*}{ Dispendukcapil } & \multicolumn{5}{|c|}{ Model Logistik } \\
\cline { 3 - 7 } & & Model I & Model II & Model III & Model IV & Model V \\
\hline 2011 & 3.022 .481 & 3.022 .481 & 3.022 .481 & 3.022 .481 & 3.022 .481 & 3.022 .481 \\
\hline 2012 & 3.125 .576 & 3.125 .566 & 3.125 .566 & 2.972 .354 & 3.004 .023 & 3.063 .683 \\
\hline 2013 & 3.200 .454 & 3.200 .440 & 3.200 .440 & 2.916 .224 & 2.984 .729 & 3.100 .536 \\
\hline 2014 & 2.853 .661 & 3.253 .908 & 3.253 .908 & 2.853 .681 & 2.964 .575 & 3.133 .402 \\
\hline 2015 & 2.943 .528 & 3.291 .629 & 3.291 .629 & 2.784 .376 & 2.943 .536 & 3.162 .632 \\
\hline
\end{tabular}

Dari Tabel 4.7 menunjukkan hasil perhitungan dari ke lima model logistik bahwa beberapa model mengalami peningkatan dan ada yang mengalami penurunan. Untuk dapat mengetahui hasil perhitungan model-model diatas yang benar-benar mendekati dengan data Dispendukcapil, maka akan ditampilkan dalam bentuk grafik pada Gambar 4.3

\section{Grafik jumlah penduduk Kota Surabaya berdasarkan model logistik dan data Dispendukcapil}

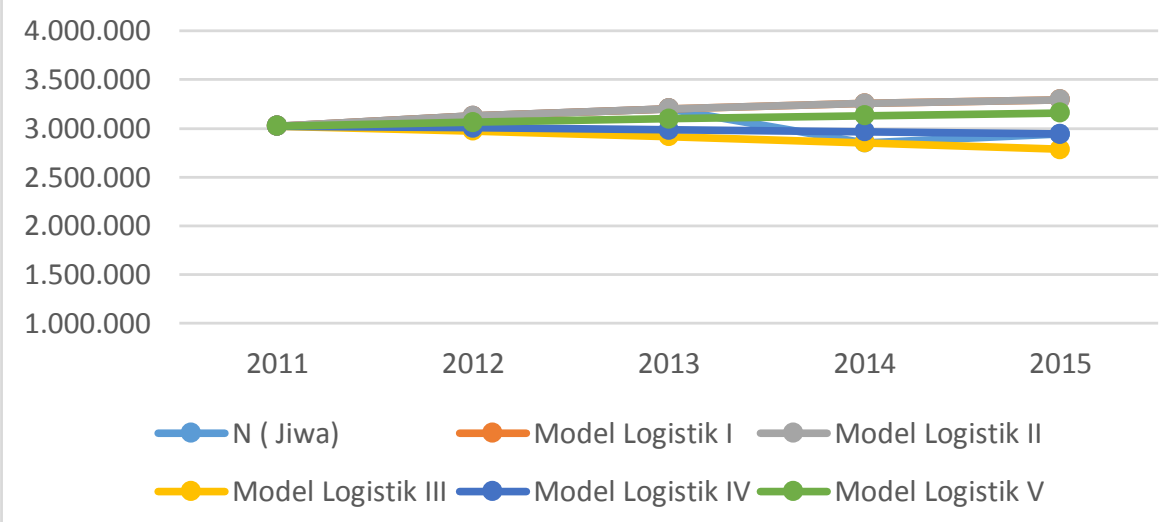

Gambar 4.3 Grafik jumlah penduduk Kota Surabaya berdasarkan data Dipendukcapil dan model logistic

Pada Gambar 4.3, terlihat bahwa grafik yang paling mendekati dengan grafik jumlah penduduk dari data Dispendukcapil adalah grafik model logistik IV. 
Jadi model logistik yang terbaik adalah model logistik IV dengan nilai laju intrinsik $k=0,05686$, atau dapat pula ditulis $P=\frac{3.388 .807}{(0,12051) e^{(0,05682) t}+1}$

\section{Perbandingan Model Logistik dan Model Eksponensial}

Berdasarkan penyelesaian kedua model populasi di atas diperoleh model populasi jumlah pnduduk Kota Surabaya yang memiliki keakuratan yang cukup signifikan dengan data sesungguhnya (data hasil sensus penduduk oleh Dipendukcapil Kota Surabaya) yaitu model eksponensial IV dengan nilai laju intinsik $k=-0,00676$ yang memiliki persamaan $P(t)=3.024 .321 e^{(-0,00676) t}$ dan model logistik dengan nilai laju intinsik $k=0,05682$ yang memiliki persamaan $P=\frac{3.388 .807}{(0,12051) e^{(0,05682) t}+1}$.

Berikut ini grafik yang menyajikan perbandingan jumlah penduduk hasil sensus dengan hasil model eksponensial IV dan model logistik IV pada Gambar 4.4

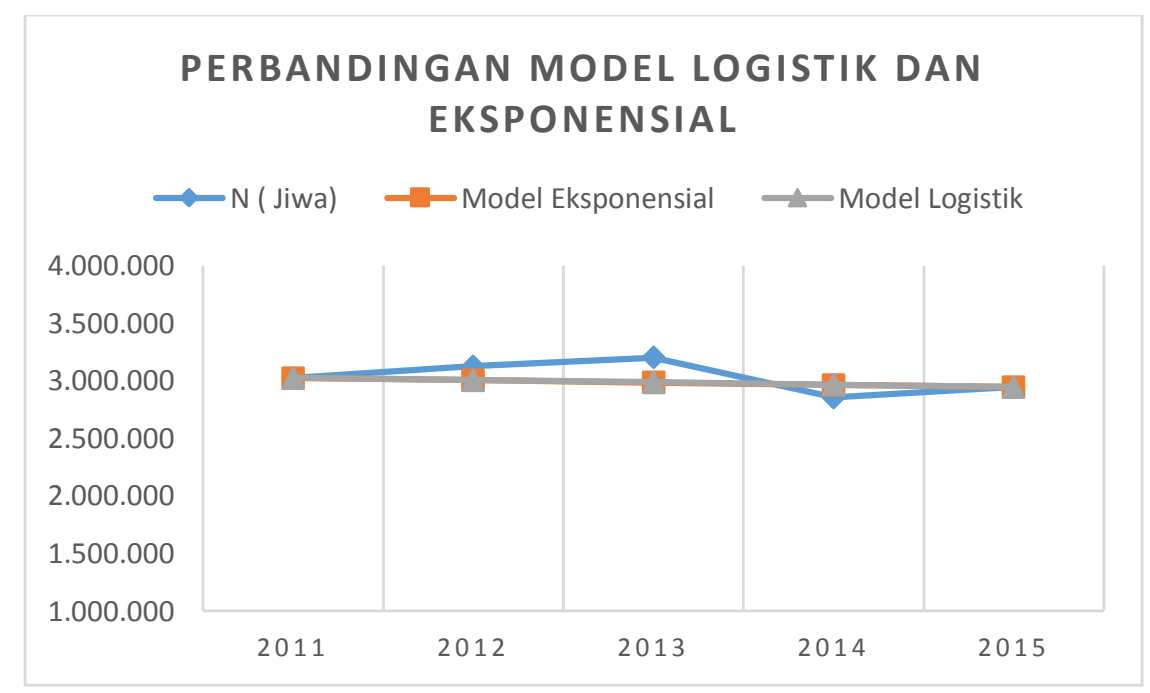

Gambar 4.4 Grafik perbandingan jumlah penduduk Kota Surabaya berdasarkan data Dipendukcapil, model eksponensial, dan model logistic

Pada Gambar 4.4 menunjukkan hasil perbandingan kedua model tersebut sama-sama mendekati data sebenarnya dan dapat digunakan untuk pendugaan jumlah penduduk yang akan datang. Meskipun keduanya model tersebut samasama memiliki galat terkecil namun dalam pendugaan jumlah penduduk Kota Surabaya untuk tahun yang akan datang model yang lebih memeiliki galat yang lebih kecil atau lebih akurat adalah model logistik. Jadi dapat disimpulkan bahwa 
model logistik adalah model yang terbaik untuk pendugaan jumlah penduduk Kota Surabaya yang akan datang.

\section{SIMPULAN}

Model pertumbuhan penduduk yang pertama diaplikasikan dalam teori persamaan diferensial yaitu model eksponensial. Dari hasil analisis diperoleh model eksponensial untuk pendugaan pertumbuhan pendududuk Kota Suarabaya dapat dituliskan $P(t)=3.024 .321 e^{(-0,00676) t}$. Model pertumbuhan penduduk yang kedua diaplikasikan dari teori persamaan deferensial yaitu model logistik. Dari hasil analisis diperoleh model eksponensial untuk pendugaan pertumbuhan pendududuk Kota Suarabaya dapat dituliskan $P=\frac{3.388 .807}{(0,12051) e^{(0,05682) t}+1}$. Dalam pengaplikasian teori persamaan deferensial telah diperoleh dua model pertumbuhan penduduk yaitu model petumbuhan penduduk eksponensial dan logistik. Selanjut kedua model tersebut dilakukan analisis dengan membandingkan hasil simulasi kedua model tersebut dengan data sebenarnya. Untuk menganalisis model yang tepat untuk menduga jumlah penduduk Kota Surabaya yaitu dengan gafik. Dari hasil analisis menunjukkan bahwa grafik model logistik yang mampunyai galat terkecil atau yang paling mendekati data sebenanya. Jadi dapat disimpulkan bahwa model yang lebih akurat untuk menduga jumlah penduduk Kota Surabaya yang akan datang adalah model logistik.

\section{DAFTAR PUSTAKA}

Ayres, Frank dkk. 1992. Persamaan Diferensial dalam satuan SI Metric. Jakarta: Erlangga

Afninisrina. 2012. Aplikasi Persamaan Deferensial Model Populasi Kontinu Pada Pertumbuhan Penduduk Jombang. Jombang: STKIP PGRI Jombang

Darmawijoyo. 2011. Persamaan Diferensial Biasa Suatu Pengantar. Jakarta: Erlangga.

Finizio, N. 1982. Persamaan Diferensial Biasa Dengan Penerapan Modern edisi kedua. Jakarta: Erlangga.

Green, L. 2002. Courses204.tersedia di http://ltcconline.net.htm [15 April 2016]. http://bappeda.jatimprov.go.id/bappeda/wp-content/uploads/potensi-kab-kota2013/kota-surabaya-2013.pdf

http://www.damandiri.or.id/file/sitiumajahmasjkuriunairbab5.pdf 
Iswadi, Rahmat. 2009. Model Pertumbuhan Penduduk Kabupaten Manokwari dan Penerapanya Dalam Pendugaan Jumlah Penduduk Beberapa Tahun Mendatang. Manukwari: Universitar Negeri Papua

Kusumah, Y. S.1989. Persamaan Diferensial. Jakarta: Depdikbud.

Kusmaryanto, Sigit. 2013. Buku Ajar Matematika Teknik 1. Malang: UB Press

Nugroho, Didi Budi. 2011. Persamaan Diferensial Biasa dan Aplikasinya Penyelesaian Manual dan menggunakan Maple. Yogyakarta: Graha Ilmu.

Moleong, Lexy J.. 2007. Metodologi Penelitian Kualitatif. Bandung: Remaja Rosdakarya.

Santoso, Widiarti. 1988. Persamaas Diferensial dengan Penerapan Modern. Jakarta: Erlangga

1997. Persamaan Diferensial Biasa. Bandung: Matematika ITB

Stewart, James. 1999. Kalkulus jilis 2. Jakarta: Erlangga

Supriyono. 2007. Persamaan Diferensial. Semarang: Universitas Negeri Semarang.

Sugiyono. 2007. Metode Penelitian Kuantitatif Kualitatif dan $R \& D$. Bandung: Elfabeta.

Waluya, S. B. 2006. Persamaan Diferensial. Yogyakarta: Graha Ilmu. 